\title{
Evaluation of intraabdominal adhesion generating potentials of ankaferd and calcium alginate used as hemostatic agents
}

\author{
Durhan $\mathrm{A}^{1}$ Tuncal $\mathrm{S}^{1}$, Kismet $\mathrm{K}^{1}$, Kilicoglu $\mathrm{B}^{1}$, Barlas $\mathrm{AM}^{1}$, Onalan $\mathrm{AK}^{1}$, Temel $\mathrm{S}^{1}$, Urhan $\mathrm{MK}^{1}$, \\ Gonultas $\mathrm{MA}^{2}$, Hucumenoglu $\mathrm{S}^{2}$, Guler $\mathrm{O}^{1}$
}

Ankara Training and Research Hospital, General Surgery Department, Turkey. kilicoglubulent@yahoo.com

\begin{abstract}
Aim: The present study aimed to evaluate intra-abdominal adhesion generating potential of Ankaferd Blood Stopper (ABS), which was used as postoperative hemostatic agent in the rats that underwent surgery, in comparison with Ca-alginate.

Material and method: Totally, 30 rats were randomized into 4 groups. In the control group, $1 \times 1 \mathrm{~cm}$ peritoneum was removed from the right lower quadrant after cecal abrasion. In the other two study groups, the same procedure was performed after Ankaferd Blood Stopper and Ca-alginate application respectively. Results were evaluated both histopathologically and by adhesion scoring methods. All results underwent statistical analysis. Results: Comparing overall results, no statistically significant difference was found between the sham, control, ABS and Ca-alginate groups $(p=0.099)$. Paired group comparisons revealed no statistically significant difference between the sham group and the control, ABS, and Ca-alginate groups $(p=0.222, p=0.222$, and $p=0.833$ respectively). It was observed that there was no statistically significant difference between the control and ABS groups ( $p$ $=0.505$ ), but there was a statistically significant difference between the control and Ca-alginate groups with Bonferroni correction $(p=0.028)$. Histopathological examination revealed no statistical difference between the groups. Conclusion: In conclusion, intra-abdominal adhesion generating potentials of $\mathrm{Ca}$-alginate and ABS were experimentally evaluated and macroscopic and microscopic comparisons revealed no significant difference between sham, control, Ca-alginate, and ABS groups (Fig. 8, Ref. 36). Text in PDF www.elis.sk.

Key words: Ca-alginate, Ankaferd Blood Stopper, adhesion, hemostatic agent.
\end{abstract}

Peritoneal adhesions can be defined as abnormal fibrous bands between intra-abdominal organs or tissues, which are normally separate from each other. Postoperative adhesions appear as a result of cellular and biochemical responses that occur while peritoneum is tried to be repaired following a trauma to peritoneal space (1). Adhesions, which have a wide range of clinical course from simple abdominal complaints to intestinal obstruction, are one of the most important causes of surgical unsuccessfulness since they prolong duration of further surgical procedure and make it more dangerous (2). The most common cause of intraabdominal adhesions is the surgical procedures performed previously in that region. Adhesions are likely to occur in approximately $90 \%$ of the patients that had undergone surgical procedure in the past $(3,4)$.

In the developed countries, intra-abdominal adhesions are the most common causes of intestinal obstructions and account for approximately $65-75 \%$ of the cases. In general, patients that are exposed to lower abdominal or pelvic interventions, which cause damages on large peritoneal surfaces, are at higher risk for

${ }^{1}$ Ankara Training and Research Hospital, General Surgery Department, Turkey, and ${ }^{2}$ Ankara Training and Research Hospital, Pathology Department, Turkey

Address for correspondence: B. Kilicoglu, Dr, Ankara Training and Research Hospital, General Surgery Department, Ulucanlar, Altindag 06370, Turkey. Phone: +903125953449 adhesive obstruction (5). Intra-abdominal adhesions following abdominal surgeries are the main causes of not only mechanical intestinal obstructions $(6,7)$, but also primary and secondary infertility in women $(8,9)$ and surgical difficulties encountered during laparotomies (10).

Today, postoperative peritoneal adhesions, which are substantial causes of morbidity and mortality, appear as one of the serious problems of surgery that remains to be solved. Until today, various pharmacological agents and methods have been used for the prevention and prophylaxis of postoperative intra-peritoneal adhesions. However, different results obtained from these studies make the prevention of postoperative intra-abdominal adhesions an issue that modern surgery is focused on.

Ankaferd Blood Stopper ${ }^{\circledR}(\mathrm{ABS})$ is an herbal-originated topical hemostatic agent that has become available in clinical use in the recent years. It provides hemostasis, independent form coagulation factors, by enabling focal erythrocyte aggregation via encapsulated protein network (11). Contents of the extract have certain special effects on endothelium, blood cells, angiogenesis, cellular proliferation, vascular dynamics and intercellular interaction. ABS shows efficacy over both fibrinogen and agglutinating proteins. Blood cells and blood proteins help ABS to generate network configuration in bleeding area. There are limited numbers of studies about clinical and experimental use of ABS in the abdomen and in hepatic surgery (12-14). 
Ca-alginate dress (Sorbalgon ${ }^{\circledR}$, Hartmann, USA) is a topical hemostatic agent and shows efficacy by releasing $\mathrm{Ca}$ ion into the media and provides coagulation (15). Alginate is composed of $\alpha$-L-glucuronic acid and $\beta$-D-mannuroic acid monomers produced from seaweed. In the recent years, alginate fibres are being widely used in the production of wound dress (16).

In the present study, we aimed to comparatively evaluate intra-abdominal adhesion generating potentials of ABS and Calcium alginate, which are used as postoperative hemostatic agents in rats that underwent abdominal surgical procedure.

\section{Material and method}

\section{Experimental plan and surgical intervention}

The present study was conducted in the General Surgery Clinic and was approved by the ethical committee of hospital. Totally, 30 Wistar Albino female rats with the mean weight of $225 \pm 25 \mathrm{~g}$ were used. Rats were randomized into four groups and kept in cages at $21 \pm 2{ }^{\circ} \mathrm{C}$ in 12-hour day and 12-hour night period.

Surgical intervention was performed under sterile conditions by the same team. All rates were famished for 12 hours prior to the surgical intervention. Rats received no enteral and/or parenteral antibiotic in the course of study. Anesthesia was provided by the mixture of $30 \mathrm{mg} / \mathrm{kg}$ ketamine hydrochloride (Ketalar ${ }^{\circledR}$; ParkeDavis, Istanbul, Turkey) and $5 \mathrm{mg} / \mathrm{kg}$ xylasine (Rompun ${ }^{\circledR}$, Bayer, Istanbul, Turkey) given via intramuscular route.

The rats $(\mathrm{n}=30)$ were randomized into four groups. After preoperative preparation, abdominal hair was shaved, the skin was sterilized with betadine solution, the abdomen was accessed through an incision, and abrasion was performed on the anterior surface of cecum using sterile gauze until subserosal haemorrhage occurred. A 1x1 cm peritoneal piece was removed from the opposite side of cecal abrasion area. This procedure was standard in the rats of all groups. Subsequent procedures performed in the groups were as follows:

Group (Sham): Six rats in this group underwent laparotomy; cecum was removed and re-located into the abdomen without any intervention.

Group (control): Eight rats in this group underwent no procedure following cecal abrasion and peritoneal resection.

Group (Ankaferd Blood Stopper group): Cecum was covered with Ankaferd blood stopper dress after cecal abrasion and peritoneal resection in the eight rats of this group.

Group (Ca-alginate group): Cecum was covered with calcium alginate dress after cecal abrasion and peritoneal resection in the eight rats of this group.

\section{Evaluation}

The rats were put into the cages after the study. They were monitored in the rooms at $22-24{ }^{\circ} \mathrm{C}$ temperature and with controlled air conditioning. Oral feeding started on the postoperative first day. Standard rat diet was given for 21 days. The rats, which were famished for one day, were sacrificed on the postoperative 21st day via high-dose diethyl ether inhalation under sterile conditions. Abdomens of the rats were accessed through a U-shape incision beginning from the pelvis and extending bilaterally to the costal curves. Adhesion was scored by a surgery team blind for the groups using a scoring method on the basis of extensiveness, appearance and resistance against force.

\section{Histopathological examination}

Tissue samples of $1 \times 1 \mathrm{~cm}$, which were taken from the peritoneum and from cecal region with subserosal hemorrhage, were fixed in $10 \%$ formaldehyde solution and then $5 \mu \mathrm{m}$ sections were obtained from paraffin-embedded tissues. Tissue sections were examined after being stained with Hematoxylen/Eosin (H/E) and Trichrom stains. The presence of inflammation in H/E stained sections and presence of fibrosis in $\mathrm{H} / \mathrm{E}$ and Trichrom stained sections were evaluated by semi-quantitative scoring system $(17,18)$.

\section{Statistical analyses}

Statistical analyses were done using SPSS 15.0 for Windows program. Numeric values were represented as n (number of rats), mean \pm standard deviation, mean, and percentage (\%). Overall comparison of the groups was done using "Kruskal Wallis Test". Paired comparisons of the groups were done by "Mann Whitney U Test". Based on the results of analyses, the $p$ value $<0.05$ was considered statistically significant. However, Bonferroni correction was used for the comparison of probable two groups and $p$ value was divided by the number of comparisons.

\section{Results}

All rats were sacrificed on the 21 st day via high-dose diethyl ether inhalation. One rat in the sham group died on the postoperative 1 st day.

\section{Adhesion Score}

Overall comparison of the groups revealed no statistically significant difference between the sham, control, ABS and Caalginate groups $(\mathrm{p}=0.099)$. Paired comparisons of the groups revealed no statistically significant difference between the sham group and the control, ABS and Ca-alginate groups $(\mathrm{p}=0.222, \mathrm{p}$ $=0.222$, and $p=0.833$ respectively). It was observed that there was no statistically significant difference between the control and ABS group $(p=0.505)$, but there was a statistically significant difference between the control group and Ca-alginate groups with bonferroni correction $(p=0.028)$. No statistically significant difference was observed also between ABS and $\mathrm{Ca}$-alginate groups $(\mathrm{p}=0.083)($ Figs 1 and 2).

\section{Results of histopathological evaluation}

Fibrosis and adhesion scores according to the groups are given in the Figures 3 and 4, mean pathology scores are given in the Figure 5. Overall comparisons of the groups revealed no significant difference between the sham, control, ABS and Ca-alginate groups $(\mathrm{p}=0.976$ for fibrosis and $\mathrm{p}=0.181$ for inflammation). With regard to paired group comparisons, no statistically significant difference was found between sham and the control $(p=0.833$ for fibrosis and $p=0.524$ for inflammation), sham and ABS ( $p=0.943$ for 


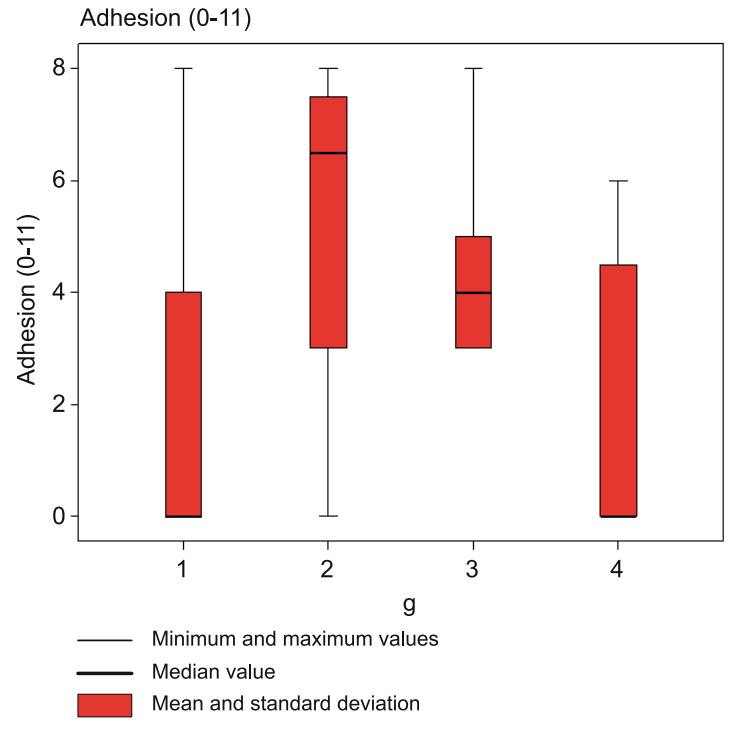

Fig. 1. Mean, standard deviation, median, minimum and maximum values of adhesion scores of the groups (Group 1: sham, 2: control, 3: ABS, 4: Ca-alginate).

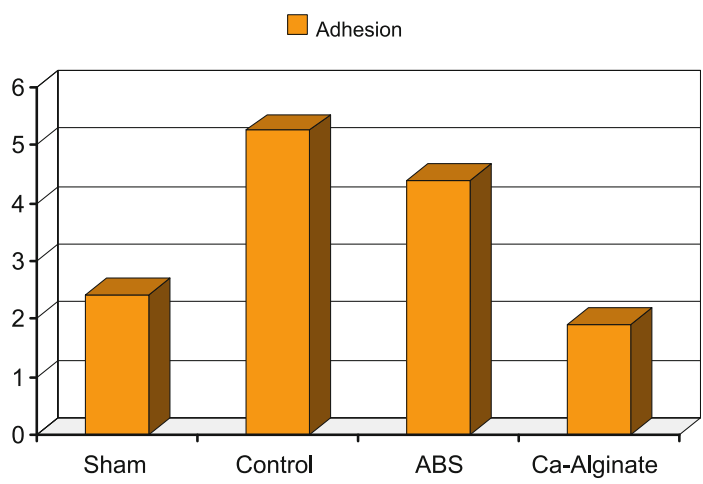

Fig. 2. Comparison of mean adhesion scores of the groups.

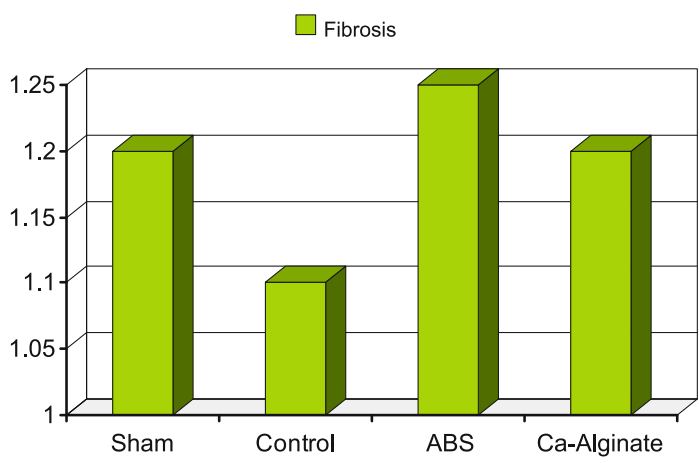

Fig. 3. Comparison of the mean fibrosis scores of the groups.

fibrosis and $\mathrm{p}=0.171$ for inflammation), and sham and Ca-alginate groups ( $p=1.00$ for fibrosis and $p=0.127$ for inflammation). There was no statistically significant difference also between the control group and ABS group $(p=0.721$ for fibrosis and $p=0.328$ for inflammation), control group and Ca-alginate group $(\mathrm{p}=0.798$

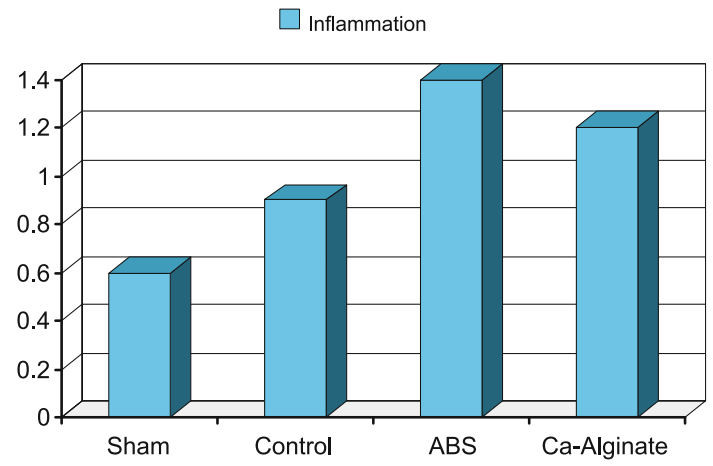

Fig. 4. Comparison of the mean inflammation scores of the groups.

$\square$ Sham $\square$ Control $\square$ ABS $\square$ Ca-Alginate

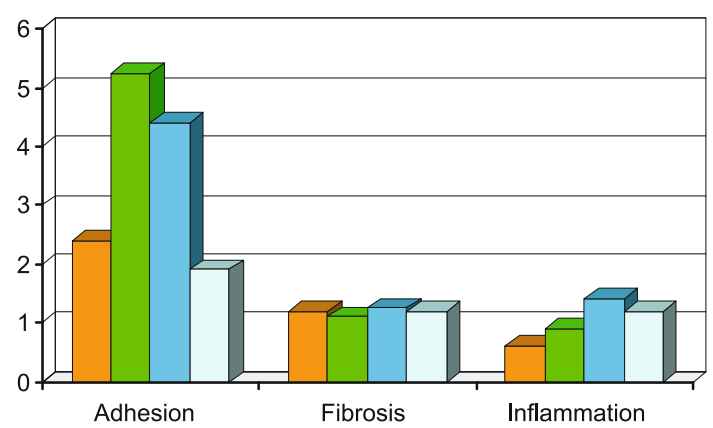

Fig. 5. Comparison of the mean adhesion, fibrosis and inflammation scores of all groups.

for fibrosis and $\mathrm{p}=0.328$ for inflammation), and finally between ABS group and Ca-alginate group $(\mathrm{p}=0.959$ for fibrosis and $\mathrm{p}=$ 0.878 for inflammation) (Figs $6-8$ ).

\section{Discussion}

Peritoneal adhesions can be defined as abnormal fibrous bands between intra-abdominal organs or tissues, which are normally separate from each other. Postoperative adhesions appear as a result of cellular and biochemical response that occurs while peritoneum tries to be repaired following a trauma to peritoneal space. Adhesions may either be congenital or acquired; most of them appear as a result of peritoneal injury and the most common cause of peritoneal injury is abdominopelvic surgery. Adhesions may less commonly occur due to inflammatory events, intraperitoneal infections or abdominal trauma. The degree of adhesion shows variation among subjects; it is also associated with the presence of complications, as well as the type and magnitude of surgical procedure. Another surgical factor that has been demonstrated to cause adhesion formation is the foreign bodies such as mesh, glove powder, suturing materials, and bile stones (1).

Most of the patients that develop adhesion are asymptomatic. However, adhesions may be important causes of morbidity and mortality in the remaining (1).

Intra-abdominal adhesions accounted for $74 \%$ of the cases in an intestinal obstruction series consisted of 552 patients. 

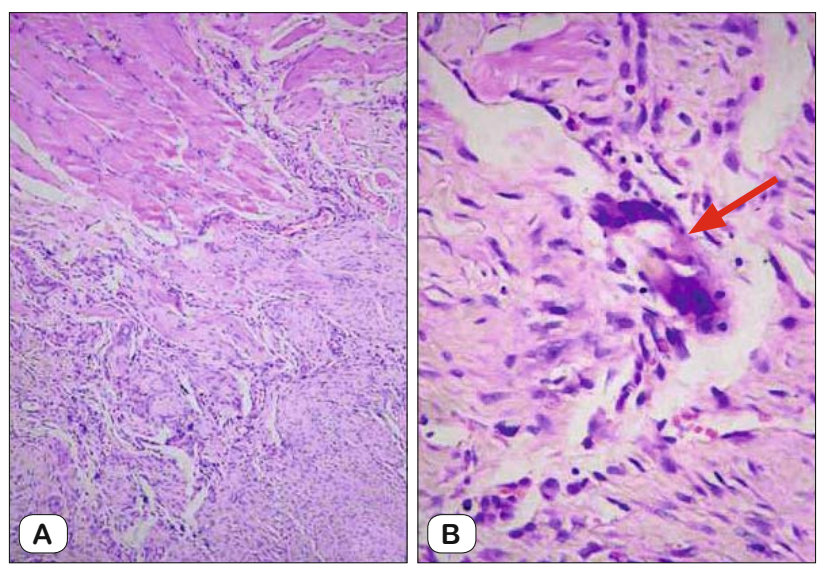

Fig. 6. Mild serosal inflammation- inflammation score 1. (Hematoxylin\&Eosin, H\&E). A. Cells that form the inflammation accompanied by fibrosis consisted of few lymphocytes and plasma cells in addition to foreign body-type multinuclear giant cells (x100). B. A histiocytic multinuclear giant cell that phagocyted foreign body (arrow) (x400).
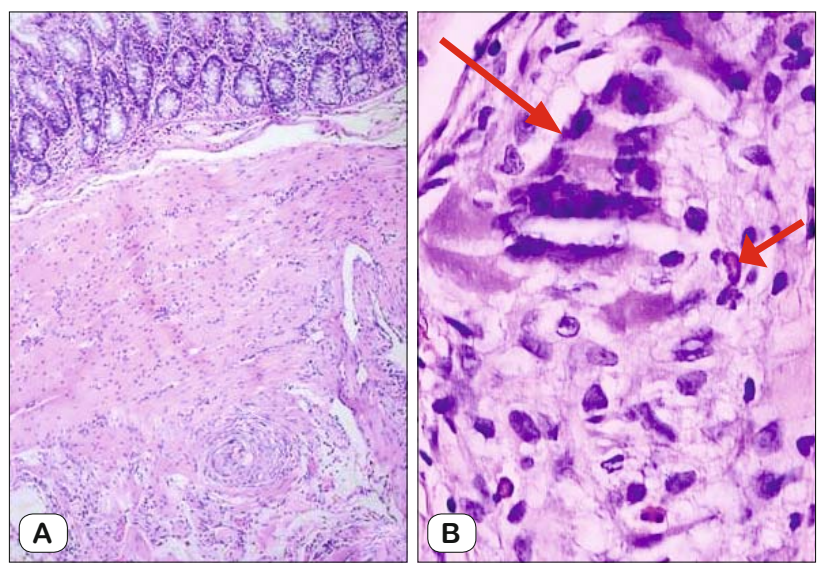

Fig. 7. Moderate inflammation- inflammation score 2. (H\&E). A. Inflammation focus close to the serosal surface of colonic wall is seen (x100). B. Cells that form the inflammation consist of foreign bodytype multinuclear giant cells (long arrow), eosinophil leukocytes (short arrow), lymphocyte, and plasma cells $(\mathbf{x 1 0 0 0 )}$.
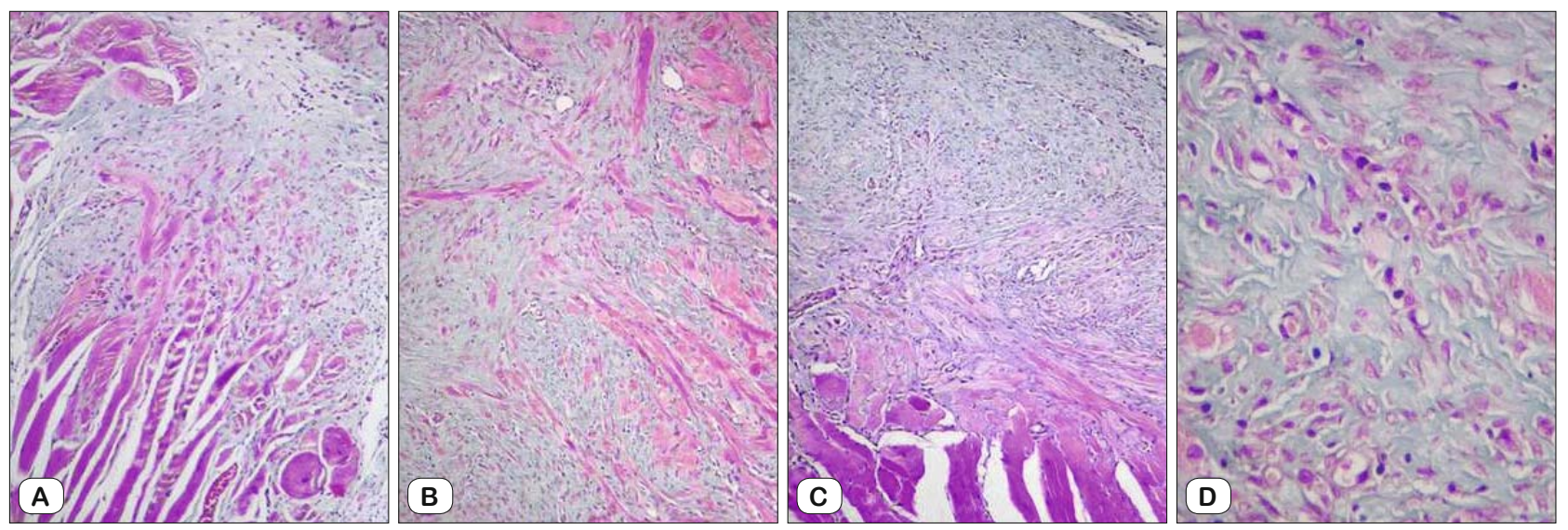

Fig. 8. With histochemical Trichrom staining, collagen-type fibrosis is seen in green fibres and residual muscle fibres are seen in red. A. Mild fibrosis formation-fibrosis score 1 (x100). B. Moderate fibrosis formation-fibrosis score 2 (x100). C,D. Severe fibrosis formation-fibrosis score $3(\mathbf{x 1 0 0}, \mathbf{x 4 0 0 )}$.
In general, some patients are more prone to develop adhesion. However, there is no marker or imaging method that would predict the development, extensiveness or severity of adhesions in the pre-operative period (19).

Recent studies determined that fibroblasts in adhesions have lower levels of nitric oxide as compared to normal peritoneal fibroblasts (17).

Saed et al (20) found tissue oxygen level as 6-8\% in the peritoneum of abdominal wall that is distant from the incision, whereas $2-3 \%$ in damaged tissues such as peritoneal incision, devascularized ovary and worn cecum. They demonstrated that tissue nitric oxide levels were remarkably decreased in line with oxygen levels.

Local intraperitoneal oxidative stress contributes to peritoneal adhesion formation. Peritoneal oxidative stress enhances adhesion formation not only via impaired mesothelial fibrinolytic activity but also by angiogenic factors that leads to over-healing of the peritoneum (21). Roy et al demonstrated increased levels of nitrotyrosine in human samples of peritoneal adhesion and this finding has provided new information about the role of free radicals in adhesion formation (21). Vural et al. conducted a study giving intraperitoneal cyclophosphamide 2 days before the study, and found that this application substantially reduced adhesion formation, and demonstrated that neutrophiles played an important role in the dynamic process in adhesion formation (22). Neutrophiles usually act by producing free oxygen radicals. The fact that free oxygen radical scavengers remarkably reduces adhesion formation has been demonstrated in the experimental models of ileal ischemiareperfusion and endometriosis $(23,24)$. In addition to cytotoxic effect of free oxygen radicals on mesothelial cells, their apoptosis inducing effects have also been demonstrated. These mechanisms lead to further progression of mesothelial damage, which occurs during surgery, and enhance postoperative adhesion. Free oxygen radicals not only cause mesothelial cellular death but also have unfavourable effects on fibrinolytic characteristics of mesothelium. Free oxygen radicals inhibit fibrinolysis by enhancing release of plasminogen activator inhibitor from the mesothelial cells. 
Alginate is a natural polysaccharide derived from seaweed, composed of $\alpha$-L-glucuronic acid and $\beta$-D-mannuroic acid monomers, and is biodegradable. This compound is used in pharmaceutical industry as a gelling and stabilizing agent. In the recent years, alginate fibres are being widely used in the production of wound dress $(16,25)$.

The main mechanism of action of many of local hemostatic substances is enabling the release of natural hemostatic mediators by means of contacting with thrombocytes and activating them. Some substances have auxiliary mechanisms of action (26).

$\mathrm{Ca}$-alginate shows hemostatic efficacy by releasing $\mathrm{Ca}$ ion into the media. $\mathrm{Ca}$ ion, which passes into the media being replaced by sodium, enhances coagulation by activating thrombocytes, factor VII, IX and X. Effect of alginate on coagulation is enhanced as its $\mathrm{Ca}$ content is increased $(15,27)$.

Ankaferd Blood Stopper, which is considered as the invention of the century, is a standard herbal content stable and sterile medical product with an immediate hemostatic efficacy, which functions as hemostasis regulator, used to control minor and major bleeding in extracorporeal wounding, traumatic incisions, dental surgeries, and after surgical procedures, as well as spontaneous bleeding.

In the present study, we investigated potential intra-abdominal adhesion generating efficacies of Ankaferd Blood Stopper and Caalginate after abdominal surgeries. The groups were separately underwent macroscopic and microscopic evaluation. The results were compared between the groups and with similar previous studies.

Adhesions in the present study have occurred between the damaged cecum serosa and peritoneum or small intestine.

Overall or paired comparisons of the groups, which were performed based on macroscopic examination, revealed no statistically significant difference $(\mathrm{p}>0.05)$.

No statistically significant difference was observed with overall and paired comparisons of the groups also in terms of histopathological microscopic examination $(\mathrm{p}>0.05)$.

Macroscopic and histopathological examinations revealed no signs of local irritation, infection or abscess. Necrosis, which is likely to occur after suturing, cauterization, ligation, or the use of inorganic topical hemostasis, was not observed in the present study.

Soga et al used Ca-alginate as endovascular embolization material in their experimental model of aneurism and reported favourable outcomes (28).

Ingram et al. implanted Ca-alginate into the anal canal after hemorrhoidectomy and compared it to the standard gauze in terms of the amount of bleeding and pain. Although they reported lower pain in Ca-alginate group, they concluded that it had no efficacy on postoperative bleeding (29).

Unlike with the present study, Kinaci et al demonstrated in their study named "efficacy of Ca alginate in hepatic parenchymal bleeding" that Ca-alginate caused massive fibrosis and adhesion in the tissue where it was attached (30). Moreover, Gaserod et al. demonstrated bioadhesive characteristic of Ca-alginate in their experimental study (31).

In the experimental study conducted by Cömert et al using single-dose ankaferd ( $3 \mathrm{ml})$, more favourable outcomes were ob- tained with Ankaferd Blood Stopper versus the control group and physiological saline group. The degree of adhesion was found to be lower. Toxic effects were not observed despite the presence of minor inflammatory changes (32).

Akarsu et al. conducted an experimental study and demonstrated that ABS had similar topical hemostatic efficacy with physiological saline in a rat model of hepatic laceration and that there was no statistical difference between the groups in terms of intra-abdominal adhesion and histopathological effects (33).

Comparison of ABS with suture material in a rat model of partial hepatic resection demonstrated that ABS had similar efficacy with oxidized cellulose in hepatic laceration model and in the rats with partial nephrectomy that received intravenous heparin anticoagulant, and did not cause fibrosis, inflammation or tissue injury (34).

ABS has been demonstrated to be clinically effective in the gastrointestinal tract in endoscopic procedures, in hepaticojejunostomy, in Dieulafoy lesion and in solitary rectal ulcer bleeding (34-36). These findings suggested that ABS can be used in laparoscopic and endoscopic surgical procedures.

In conclusion, intra-abdominal adhesion generating potentials of Ca-alginate and ABS have been experimentally evaluated and no significant difference was found between sham, control, $\mathrm{Ca}$-alginate and $\mathrm{ABS}$ groups in macroscopic and microscopic comparisons.

Potential adverse events, such as adhesion, abscess formation and fluid collection, should be taken into consideration in the clinical use of a topical hemostatic material, such as ABS, which acts by forming protein network and of which intra-abdominal usage may require high amounts. More detailed studies about its use in different doses are required.

Not observing adhesion enhancing effect of Ca-alginate in the present study unlike other studies means not only that it can be safely used in intra-abdominal procedures but also more comprehensive studies that would be performed in larger numbers of subjects are needed.

Although we observed macroscopic and microscopic favourable effects of ABS in intra-abdominal use, we think that safety and efficacy of ABS in abdominal surgeries in human can be demonstrated in more comprehensive studies.

\section{References}

1. Attard JA, MacLean AR. Adhesive small bowel obstruction: epidemiology, biology and prevention. Canad J Surg 2007; 50 (4): 291-300.

2. Cheadle WG, Garr EE, Richardson JD. The importance of early diagnosis of small bowel obstruction. Amer Surg 1988; 54 (9): 565-569.

3. Ellis H. The cause and prevention of postoperative intraperitoneal adhesions. Surg Gynecol Obstet 1971; 133 (3): 497-511.

4. Menzies D, Ellis H. Intestinal obstruction from adhesions--how big is the problem? Ann Roy Coll Surg Engl 1990; 72 (1): 60-63.

5. Dijkstra FR, Nieuwenhuijzen M, Reijnen MM, van Goor H. Recent clinical developments in pathophysiology, epidemiology, diagnosis and treatment of intra-abdominal adhesions. Scand J Gastroenterol 2000; Suppl (232): 52-59. 
6. Rivkind AI, Lieberman N, Durst AL. Urokinase does not prevent abdominal adhesion formation in rats. Eur Surg Res 1985; 17 (4): 254-258.

7. Raf LE. Causes of abdominal adhesions in cases of intestinal obstruction. Acta Chir Scand 1969; 135 (1): 73-76.

8. Asherman JG. Traumatic intra-uterine adhesions. J Obstet Gynaec Brit Empire 1950; 57 (6): 892-896.

9. Poon HK. Intraperitoneal adhesions: a challenge to the surgeon - presentation of three cases and review of literature. Maryland State Med J 1977; 26 (5): 75-80.

10. Yaffe H, Beyth Y, Reinhartz T, Levij IS. Foreign body granulomas in peritubal and periovarian adhesions: a possible cause for unsuccessful reconstructive surgery in infertility. Fertil Steril 1980; 33 (3): 277-279.

11. Goker H, Haznedaroglu IC, Ercetin S, Kirazli S, Akman U, Ozturk Y et al. Haemostatic actions of the folkloric medicinal plant extract Ankaferd Blood Stopper. J Intern Med Re 2008; 36 (1): 163-170.

12. Matsuda H, Ando S, Kato T, Morikawa T, Yoshikawa M. Inhibitors from the rhizomes of Alpinia officinarum on production of nitric oxide in lipopolysaccharide-activated macrophages and the structural requirements of diarylheptanoids for the activity. Bioorg Med Chem 2006; 14 (1): $138-142$.

13. Testai L, Chericoni S, Calderone V, Nencioni G, Nieri P, Morelli I et al. Cardiovascular effects of Urtica dioica L. (Urticaceae) roots extracts: in vitro and in vivo pharmacological studies. J Ethnopharmacol 2002; 81 (1): 105-109.

14. Sheela ML, Ramakrishna MK, Salimath BP. Angiogenic and proliferative effects of the cytokine VEGF in Ehrlich ascites tumor cells is inhibited by Glycyrrhiza glabra. Intern Immunopharmacol 2006; 6 (3): 494- 498.

15. Born GV, Cross MJ. Effects of Inorganic Ions and of Plasma Proteins on the Aggregation of Blood Platelets by Adenosine Diphosphate. J. Physiol 1964; 170: 397-414.

16. Gilchrist T, Martin AM. Wound treatment with Sorbsan--an alginate fibre dressing. Biomaterials 1983; 4 (4): 317-320.

17. Saed GM, Abu-Soud HM, Diamond MP. Role of nitric oxide in apoptosis of human peritoneal and adhesion fibroblasts after hypoxia. Fertil Steril 2004; 82 (Suppl 3): 1198-1205.

18. ten Raa S, van den Tol MP, Sluiter W, Hofland LJ, van Eijck CH, Jeekel $\mathbf{H}$. The role of neutrophils and oxygen free radicals in post-operative adhesions. J Surg Res 2006; 136 (1): 45-52.

19. Alpay Z, Saed GM, Diamond MP. Postoperative adhesions: from formation to prevention. Semin Reprod Med 2008; 26 (4): 313-321.

20. Saed GM, Galijasevic S, Diamond MP, Abu-Soud HM. Measurement of oxygen and nitric oxide levels in vitro and in vivo: relationship to postoperative adhesions. Fertil Steril 2005; 84 (1): 235-238.

21. Roy S, Clark CJ, Mohebali K, Bhatt U, Wallace WA, Nahman NS et al. Reactive oxygen species and EGR-1 gene expression in surgical postoperative peritoneal adhesions. World J Surg 2004; 28 (3): 316-320.

22. Vural B, Canturk NZ, Esen N, Solakoglu S, Canturk Z, Kirkali $\mathbf{G}$ et al. The role of neutrophils in the formation of peritoneal adhesions. Hum Reprod 1999; 14 (1): 49-54.
23. Tsimoyiannis EC, Tsimoyiannis JC, Sarros CJ, Akalestos GC, Moutesidou KJ, Lekkas ET et al. The role of oxygen-derived free radicals in peritoneal adhesion formation induced by ileal ischaemia/reperfusion. Acta Chir Scand 1989; 155 (3): 171-174.

24. Portz DM, Elkins TE, White R, Warren J, Adadevoh S, Randolph J. Oxygen free radicals and pelvic adhesion formation: I. Blocking oxygen free radical toxicity to prevent adhesion formation in an endometriosis model. Intern J Fertil 1991; 36 (1): 39-42.

25. Y Q. Absorption Characteristics of alginate wound dressings. J App Polymer Sci 2003; 91: 953-957.

26. Ayşan E KK, Kinaci E, Başak $F$ et al. Karaciğer parenkim kanamasinin engellenmesinde alüminyum sulfatin etkinliği. Ulusal Cerrahi Dergisi 2004; 20: 147-152.

27. Jarvis PM GD, Blair SD, McCollum CN. How does calcium alginate achieve haemostasis in surgery? Thromb Haemost 1987; 58: 108.

28. Soga Y, Preul MC, Furuse M, Becker T, McDougall CG. Calcium alginate provides a high degree of embolization in aneurysm models: a specific comparison to coil packing. Neurosurgery 2004; 55 (6): 1401-1409.

29. Ingram M, Wright TA, Ingoldby CJ. A prospective randomized study of calcium alginate (Sorbsan) versus standard gauze packing following haemorrhoidectomy. J Royal Coll Surg Edinburgh 1998; 43 (5): 308-309.

30. Kinaci E. Karaciğer parankim kanamasinda kalsiyum alginatin etkinliği [Uzmanlik Tezi]: İstanbul Eğitim ve Araştirma Hastanesi; 2007: 1; 1-40.

31. Gaserod O JI, Hampson FC, Dettmar PW et al. Enhancement of the bioadhesive properties of calcium alginate gel beads by coating with chitosan. Int J Pharm Res 1998; 175: 237-246.

32. Cömert M, Karakaya K, Barut F, Karadeniz ÇG, Uçan HB, Gültekin F. A, Emre Uğur A, Taşçilar Ö, Irkörücü O, Ankarali H. Does intraabdominal use of Ankaferd Blood Stopper cause increased intraperitoneal adhesions? Ulus Travma Acil Cerrahi Derg 2010; 16 (5): 383-389.

33. Akarsu C, Yavuz E, Özkara S, Gökçek B, Özdenkaya Y, Yalçin O. Siçanlarda karaciğer laserasyon modelinde Ankaferd Blood Stopper ve fibrin yapiştiricinin hemostatik etkinliğinin karşilaştirilmasi. Ulus Travma Acil Cerrahi Derg 2011; 17 (4): 308-312.

34. Kurt M, Kacar S, Onal IK, Akdogan M, Haznedaroglu IC. Ankaferd Blood Stopper as an effective adjunctive hemostatic agent for the management of life-threatening arterial bleeding of the digestive tract. Endoscopy 2008; 40 (Suppl 2): E262.

35. Kurt M, Disibeyaz S, Akdogan M, Sasmaz N, Aksu S, Haznedaroglu IC. Endoscopic application of ankaferd blood stopper as a novel experimental treatment modality for upper gastrointestinal bleeding: a case report. Amer J Gastroenterol 2008;103 (8): 2156-2158.

36. Ibis M, Kurt M, Onal IK, Haznedaroglu IC. Successful management of bleeding due to solitary rectal ulcer via topical application of Ankaferd blood stopper. J Altern Complement Med 2008; 14 (9): 1073-1074.

Received July 12, 2013. Accepted September 20, 2013. 